\title{
PHARMACEUTICALS IN AQUATIC ENVIRONMENT. FATE AND BEHAVIOR, ECOTOXICOLOGY AND RISK ASSESSMENT - A REVIEW
}

\author{
BARBARA GWOREK, MARTA KIJEŃSKA*, MAGDALENA ZABOROWSKA, \\ JUSTYNA WRZOSEK, LIDIA TOKARZ and JAROSŁAW CHMIELEWSKI
}

Institute of Environmental Protection - National Research Institute, Krucza 5/11 d, Warsaw, Poland

\begin{abstract}
Pharmaceuticals are long-lasting, biologically active substances that, when discharged into the natural environment, affect ecosystem stability. The presence of increasing amounts of pharmaceuticals and their transformation products in the environment has been a subject of growing interest. Many of the commonly used pharmaceuticals, especially analgesics and antibiotics, are used in quantities similar to those of agricultural chemicals but are not required to undergo the same level of environmental risk assessment. The fate and behavior of medicines in the environment require further research. Human and veterinary pharmaceuticals and their metabolites are distributed in the environment in various ways. The incidence of medicines and their transformation products has been so far recorded in surface and ground waters, drinking water, bottom sediments, soils, wastewater, and sewage sludge, as well as in animal organisms. The article presents issues related to the fate and behavior of pharmaceuticals both in the environment and in the processes of wastewater treatment, ecotoxicology and risk assessment.
\end{abstract}

Keywords: pharmaceuticals, aquatic environment, ecotoxicology, environmental risk

Many of the commonly used pharmaceuticals, especially analgesics and antibiotics, are used in quantities similar to those of agricultural chemicals but are not required to undergo the same level of environmental risk assessment (1). Pharmaceuticals entering the environment may undergo various reactions, and in consequence - become completely or partially degraded (2). Degradation is a gradual decay of a particle through the elimination of its individual elements, leading to more simple molecules (3). These processes may take place either biotically or abiotically (4). In consideration of the latter mechanisms, pharmaceuticals can be classified into groups, e.g. medicines and metabolites that are wholly eliminated in the process of biologicallyinduced mineralization involving the metabolic activity of bacteria, medicines completely or partially degraded and those that remain persistent in the environment (5). The amount of pharmaceuticals discharged into the environment exceeds transformation capability in the environment (2). Different medicine classes vary in terms of the degree of biological and chemical transformation (6).
Fate and behavior of pharmaceuticals in water

The amounts of medicine residues in the environment depends primarily on quantity of the pharmaceuticals produced and discharged into the environment, their degradation, partial decomposition, as well as dissolution processes decreasing concentrations of these chemical substances in a given environmental medium (water, sediment, soil) (6). The processes described above bring about everincreasing amounts of the discussed chemicals in the environment, even though their durability is by and large relatively low. In most cases, the processes leading to the reduction of pharmaceutical amounts in the environment include biodegradation, hydrolysis and direct or indirect photodegradation of these substances. For example, due to poor ability to hydrolyze, pharmaceutical compounds are abiotically transformed in the surface waters mainly through photolysis. This process takes place both in natural waters and wastewaters $(2,6)$. Some of medicines discharged into the environment are resistant to photolysis (diclofenac, carbamazepine).

\footnotetext{
* Corresponding author: e-mail: marta.kijenska@ios.edu.pl
} 
Boreen et al. (7) found that photochemical degradation can be a key mechanism for the removal of many pharmaceutical substances from the surface waters. Bottoni and Caroli reported that the degradation rate due to photolysis was thought to be 11$23 \%$ in $34 \mathrm{~h}(8)$.

One of the major problems for the environment among the pharmaceuticals are antibiotics (9). Special attention is paid to the this group of medicines, because although the concentration of the antibiotics in the environment is not significant (usually at $\mathrm{ng} / \mathrm{L}$ to $\mathrm{mg} / \mathrm{L}$ in water) (10), one have to remember that the continuous exposure to even low concentrations may cause the danger of the emergence of resistant strains (11). Sulfonamides and fluoroquinolones are the most persistent pharmaceuticals in the environment. Tetracyclines, fluoroquinolones, aminoglycosides, sulfonamides, macrolides and $\beta$-lactams are most easily absorbed by sediments and soils (2). Antibiotics discharged into the soil undergo sorption or degradation, or else are mobile in the soil solution. Starting from the soil environment, pharmaceutical compounds can penetrate waters including groundwaters (2). The majority of antibiotics does not undergo degradation or transformation processes and remain permanently in the soil even for the period of several months. This phenomenon is dependent on the ambient temperature and the chemical structure of a given pharmaceutical. Once in the soil, tetracyclines tend to accumulate due to their low degradation rates and also e.g. their high content in manure that is every so often used as a soil fertilizer. They are also strongly adsorbed on the surface of soil solution components, and then the penetration into deeper soil layers or groundwater is held back. High tetracycline quantities accumulate mainly in the soil arable layer. A similarly high sorption index is characteristic of ciprofloxacin and norfloxacin, which are not degraded during wastewater treatment but are adsorbed on sewage sludge deposited into the soil.

Medicines from the group of sulfonamides, whose content in the soil is relatively low, behave differently, and a quantity of these is recorded in groundwaters (12). Likewise, polar pharmaceutical substances such as clofibric acid, carbamazepine, primidone or iodinated contrast agents can leach from the soil into groundwater (13).

The aquatic environment is often contaminated with pharmaceutical residues. Biodegradation in bottom sediments can play a considerable role in the process of removing these substances from the rivers, which is limited due to the flow of water and pharmaceutical dissolution in the sediment environ- ment. A study was carried out to determine the combined effect (interaction) of water flow velocity and sediment dynamics on decomposition of several acidic drugs detected in the environment. An experiment was carried out with water and sediment from the river on a laboratory scale, under two types of conditions: static and at sediment motion. The halflife of 4 substances: diclofenac, bezafibrate, ibuprofen, and naproxen ranged from 2.5 to 18.6 days and these periods were shorter when the exchange of surface and pore water was rapid. For gemfibrozil, the half-life was 10.5 days in a moving sediment experiment, while no degradation of the drug was observed under static sediment conditions. This can be explained by the limited transport of the water and solute to the sediments, at low flow rates, which rapidly induces anaerobic conditions in the bottom sediment. Naproxen was the only substance effectively removed under anoxic conditions in the deeper sediment layers (14).

The potential of biodegradation and sorption of acetaminophen, caffeine, propranolol, and acebutolol in the aquatic environment was investigated under the laboratory conditions by a research team from Taiwan. All four chemicals showed great degradation and sorption potentials under natural water conditions. Biodegradation was the main mechanism of removing acetaminophen, whose half-life was 2.1 days (combined sorption and biodegradation). For comparison, after a period of 15 days, $30 \%$ decomposition was observed at acetaminophen sorption (exclusively). For caffeine, both processes were of considerable importance (half-life of 1.5 days, sorption and biodegradation together). On the other hand, in the case of propranolol and acebutolol, the sorption process proved to be an important removal mechanism as both substances were not biodegradable (15).

In Great Britain, Liu and Williams (16) evaluated the durability of pharmaceutical substances: propranolol, atenolol and metoprolol, when the samples tested were exposed to solar radiation (temperature $20-26^{\circ} \mathrm{C}$ ) under the laboratory conditions. The results suggest that direct photolysis in an optically diluted solution is consistent with first order kinetics. The half-lives of propranolol, atenolol and metoprolol were 16, 350 and 630 hours, respectively. By comparing radiation lamp intensity imitating insolation, it was proved that half-lives of the substances tested were associated with the conditions of daylight exposure, depending on the season and latitude. The main direct photolysis products were those derived from propranolol after a 46-hour exposure, which led to the identification of the reac- 
tion pathway, including oxidation, deoxidation and structure change.

Photodegradation of four pharmaceuticals (carbamazepine, ibuprofen, ketoprofen, and $17 \alpha$-ethinylestradiol) in the water environment, was analyzed under a solar simulator and natural sunlight. The experiment was carried out on water taken from the river and the sea, and distilled water was used to establish a direct path of photodegradation. The exposure time under the solar light simulator was up to 400 minutes and under natural sunlight -24 days. In all the waters tested, ketoprofen was quickly transformed as a result of the direct photolysis, during sun exposure (half-life $-t_{1 / 2}-2.4 \mathrm{~min}$ ) and simulator $\left(t_{1 / 2} 0.54 \mathrm{~min}\right)$, whereas for ketoprofen and 17 $\alpha$-ethinyl estradiol the half-life lasted from 1 to 5 hours. The half-life for the most degradation-resistant carbamazepine was 8-39 hours (17).

Kwon and Armbrust (18) studied, under the laboratory conditions, the durability and fate of fluoxetine - a drug from the class of selective serotonin reuptake inhibitors (SSRIs). Fluoxetine proved to be resistant to hydrolysis and photolysis processes in all the aqueous systems tested, with a half-life longer than 100 days, except for the synthetic humus water (21 days). Minimum degradation was observed in activated sewage sludge, however, fluoxetine was rapidly dispersed in the aqueous phase, as a result of adsorption in the sludge in the water-sediment system. The data obtained suggest that, although fluoxetine appears to be relatively stable in the laboratory systems studied, it may rapidly penetrate from water to the sediment, entering the natural water environment.

In the study by Liang et al. (19), significant differences in the distribution of antibiotics in river sediments and waters were observed. Environmental conditions have a significant impact on the distribution of antibiotics in river waters and sediments. The value of the pseudo-partition coefficient (P-PC) of norfloxacin was positively correlated with the total content of $\mathrm{C}$ in the sediments, as well as water $\mathrm{pH}$ affected the presence of hydrated erythromycin in the sediments. As a result of the high values of the adsorption coefficient (Koc) and P-PC, erythromycin and roxithromycin were found only in the sediments, whereas sulfadiazine and sulfamethoxazole were detected only in waters. The concentration of antibiotics in river sediments shows no seasonal differentiation and no reduction with increasing water salinity in the estuary. There was observed the vertical diffusion of antibiotics in the river water column, indicating higher antibiotic concentration in the surface water layers when compared to the river bot- tom. River sediments may not only be a major reservoir accumulating antibiotics, but also a potential source of discharge of these substances into the aquatic environment, on account of changing water physico-chemical conditions, as well as they may be toxic to water organisms $(\mathrm{pH}$, salinity in estuaries, etc.). For example, in the studies of Muñoz et al. (20), a relationship was found between the concentration of anti-inflammatory drugs as well as $\beta$-blockers in river waters and the populations of invertebrate benthic (bottom) organisms such as midges (Chironomus spp.) and sewage worms (Tubifex tubifex).

A team of researchers from California studied contents of 14 pharmaceuticals, personal care products as well as endocrine disrupters in wastewater and showed seasonal variability in their concentrations. The predominant drugs detected were naproxen, ibuprofen and paracetamol with higher concentrations observed in the winter season when compared to those recorded in the summer. This may be due to enhanced consumption of NSAIDs and paracetamol-containing drugs in the winter months, i.e. during the season of high influenza prevalence. Another reason for comparably higher pharmaceutical concentrations observed in wastewater during the winter, is their faster degradation in the summer, as a result of higher wastewater temperatures. In the summer, photolysis processes go through faster, at the same time as their effectiveness depends on the light intensity and incidence. Photochemical degradation takes place mainly in high transparency waters with the surface layers exposed to the sun. If the substance is sensitive to the light, the decomposition of its molecule under the influence of the sunlight can be of great importance in the process of elimination of a given compound. Photolysis can play a significant role as an additional elimination pathway, especially in the surface waters (21-22).

Intermittent changeability in the persistence of chemical pollution in the Swedish lake was examined by means of the comparative chemical analysis (23). The chemical compounds tested included 12 pharmaceuticals, artificial sweetener and a contrast agent for X-rays. Measurements were carried out in the late spring, late autumn and winter. The half-life was determined for 7 of the chemicals tested, ranging from a few to several hundred days. Five chemical substances (bezafibrate, climbazole, diclofenac, furosemide, and hydrochlorothiazide) exhibited shorter durability in the late spring when compared to that measured in the late autumn. This may be due to lower temperatures and/or lesser sun exposure in the late autumn. The seasonality of chemical dura- 
bility contributed to the changes in pharmaceutical concentrations all through the year. The effect of the seasonality of durability was compared with the influence of other important variables, determining a level of pharmaceutical contents in the lake examined: chemical discharges and water flow. The highest seasonal variation in chemical concentrations in the lake was reported for hydrochlorothiazide (23). In another study on a Swedish lake, Zou et al. (24) calculate the half-life with a $95 \%$ confidence interval for carbamazepine (780-5700 days) and ketoprofen $(<1-2$ days $)$.

Given that environmental contamination with pharmaceuticals has been increasingly affecting drinking water sources (pharmaceutical concentrations observed range from $\mathrm{ng} / \mathrm{L}$ to $\mu \mathrm{g} / \mathrm{L}$ ), and in view of still lacking knowledge on this issue, in many countries, studies have been undertaken to assess the impact of pharmaceutical substances on the quality of drinking water sources (25-26).

At the end of the 1990s, more than 40 different pharmaceutical substances were detected in treated wastewaters and the surface waters, with concentrations ranging from $\mathrm{pg} / \mathrm{L}$ to $\mu \mathrm{g} / \mathrm{L}$ (27-30).

Lam et al. (31) studied the durability of 8 pharmaceuticals from various classes under the field conditions. A method was developed to determine a mixture of acetaminophen, atorvastatin, caffeine, carbamazepine, levofloxacin, sertraline, sulphamethoxazole, and trimethoprim in the surface water. The half-life of the pharmaceuticals examined in the surface water was 1.5-82 days. The photolysis of the studied substances in sunlit surface waters constituted an important factor in limiting their durability in the aquatic environment. At the same time, the biodegradation process had no significant effects on the breakdown of the pharmaceuticals tested.

Paíga and Delerue-Matos (32) conducted a study to determine the content of pharmaceuticals in groundwaters, using samples taken in the areas of five cemeteries in Portugal. The samples showed the presence of acetaminophen, salicylic acid, ibuprofen, ketoprofen, nimesulide, carbamazepine, fluoxetine, and sertraline. No antibiotics were found. Salicylic acid and carbamazepine showed the highest concentrations (33.7-71 ng/L, 20-23.3 ng/L, respectively). Cluster analysis results indicated the similarity between carbamazepine and fluoxetine contamination, probably due to their persistence in the environment (32).

An experiment was carried out on degradation kinetics of gemfibrozil, naproxen and mefenamic acid in water samples taken from the lakes of
Table 1. Concentrations of selected pharmaceuticals in treated wastewater (based on Tixier et al. 2003).

\begin{tabular}{|c|c|}
\hline Drug & Concentration $[\mu \mathrm{g} / \mathrm{L}]$ \\
\hline Carbamazepine & 0.95 \\
\hline Clofibric acid & 0.06 \\
\hline Diclofenac & 0.99 \\
\hline Ibuprofen & 1.3 \\
\hline Ketoprofen & 0.18 \\
\hline Naproxen & 2.6 \\
\hline
\end{tabular}

Venezuela examined in the period of 150 days. It turned out that under sunlight conditions, naproxen and mefenamic acid were degraded in a fairly long time, and their half-life ranged from $9.6 \pm 0.5$ to 27 \pm 6.6 days, whereas gemfibrozil showed high stability, with a half-life ranging from $119.5 \pm 15.6$ to $288.8 \pm 61.3$ days (33).

Tixier et al. (34) measured 3-month-period concentrations of 6 pharmaceuticals: carbamazepine, clofibric acid, diclofenac, ibuprofen, ketoprofen and naproxen in treated wastewaters from 3 wastewater treatment plants, 2 rivers, and the water column of Greifensee lake in Switzerland. Table 1 shows the pharmaceutical concentrations observed in treated wastewater. The overall removal rate of pharmaceuticals was estimated in the surface waters under lake conditions, based on field measurements and modeling. Carbamazepine and clofibric acid were found to be persistent in the environment. The results of the study showed that phototransformation was the main process eliminating diclofenac from the lake waters. Ibuprofen, which is a drug with a relatively high coefficient of sorption to particles, can be eliminated by the sedimentation process (34).

Ketoprofen and naproxen can be removed by the biodegradation and phototransformation processes. Also in Switzerland, Bahnmüller et al. (35) examined the phototransformation processes in the surface water and wastewater effluent with regard to sulfadiazine and sulfamethoxazole -2 frequently used sulfonamide antibiotics. A kinetic study was carried out to identify the process responsible for phototransformation in sunlight surface waters. Under typical surface water conditions, analogous to the conditions of the Swiss river Thur, from which water samples were taken, in both sulfonamides tested, the observed half-life was 3-13 days.

Another category of pharmaceuticals are illicit drugs. Table 2 shows chosen illicit drugs, such as amphetamine, methamphetamine and ecstasy concentrations observed in wastewater (36). 


\section{Pharmaceuticals in wastewater treatment processes}

Esplugas et al. (37) analyzed the use of the ozonation technique and other advanced oxidation processes employed to eliminate pharmaceuticals, endocrine disrupters and personal care products from wastewaters. The authors show that physical separation methods, such as adsorption on activated carbon and membrane processes are effective methods for removing pharmaceutical contaminants from wastewater effluent, as well as - advanced oxidation processes. Based on the literature review, the authors state that ozonation has been the most often studied process of oxidation of pharmaceutical contaminants, and this gives good predictions for its successful application.

In Spain, a study was carried out to assess the efficiency of wastewater treatment with the use of various methods. Of 40 pharmaceuticals present in raw sewage, 28 were removed by conventional methods (filtration through a sand bed, chlorination and ozonation). Despite the use of both conventional and advanced treatment methods (including reverse osmosis, considered the most effective), some chemical compounds were still present in treated wastewater: benzoylgonine, iopromide, caffeine, nicotine, cotinine, erythromycin, and paracetamol (38).

The effluents from wastewater treatment plants in 4 European countries (France, Italy, Greece, and Sweden) were tested for the presence of pharmaceutical residues by Andreozzi et al. (39). The analyses were carried out using the GC-MS and HPLCMS/MS procedures. Over 20 pharmaceutical substances (of various therapeutic classes) were found in the effluents. Antibiotics, gemfibrozil, ibuprofen, naproxen, carbamazepine and the majority of $\beta$-blocker medications were detected in all the samples tested. The susceptibility of 6 of the pharmaceuticals detected to abiotic photodegradation was examined. Evaluations of the half-lives of carbamazepine, diclofenac, clofibic acid, sulfamethoxazole, ofloxacin and propranolol in the year seasons and at different latitudes, were carried out on the basis of quantum yield of the photodegradation

Table 2. Concentrations of selected pharmaceuticals in wastewater (based on Nowicki et al. 2014).

\begin{tabular}{|c|c|}
\hline Drug & Concentration $[\mathrm{ng} / \mathrm{L}]$ \\
\hline Amphetamine & $0.23-0.71$ \\
\hline Methamphetamine & $0.66-1.46$ \\
\hline Ecstasy & $1.02-2.03$ \\
\hline
\end{tabular}

process. The results showed that the half-life for both carbamazepine and clofibic acid was 100 days - at higher latitudes $\left(50^{\circ} \mathrm{N}\right)$, under winter conditions. Under the same conditions, the half-lives for sulfamethoxazole, diclofenac, ofloxacin, and propranolol were much shorter: 2.4, 5.0, 10.6 and 16.8 days (39).

Archer et al. (40) in their study detected 41 emerging contaminants in effluent from wastewater treatment plant and performed for them Environmental Risk Assessment. The results indicated that 5 of them posed an environmental risk ( $R Q>1$ ). These emerging contaminants included diclofenac (RQ 23.1), sulfamethoxazole (RQ 2.27), clarithromycin (RQ 2.7), codeine (RQ 5.83) and nicotine (RQ 12.86) (40).

All over the world, the use of various techniques and methods to improve elimination of antiinflammatory drugs from waters has been investigated. Research on the degradation of naproxen by means of ultrasound in the presence of carbon nanotubes or granulated activated carbon, as well as a combination of reverse osmosis or nanofiltration membrane bioreactors, are only a few of research directions, being a response to ever-increasing contamination of the aquatic environment by pharmaceuticals (41-43).

Transformation of active pharmacological compounds in the process of wastewater treatment depends on the type of wastewater and the processes that take place during the treatment. As a result of wastewater treatment, drugs and their metabolites can be degraded, mineralized to change into carbon dioxide and water, adsorbed on solid suspensions (if unwanted substances are lipophilic) or sewage sludge, or else - removed together with sewage in an unchanged form or as a product of partial degradation $(2,44)$.

Mixtures of pharmaceuticals are partially removed in wastewater treatment plants, but in any case, these substances get into the surface waters, groundwaters and sediments in an unchanged form (4, 13, 22, 45-50). For example, macrolide antibiotics are not completely removed in the wastewater treatment process, and their residues are found in the water environment $(13,45,51)$. Likewise, painkillers and anti-inflammatory drugs, resistant to biodegradation and photolysis, are often not fully removed in the wastewater treatment process. These substances penetrate into waters in the unchanged form or as metabolites $(13,46)$.

The pharmaceutical substances present in sewage affect the microfauna of activated sludge in wastewater treatment plants. Adsorption of pharma- 
ceuticals in sewage sludge depends on their hydrophobic properties and electrostatic interactions with sludge particles, as well as on the activity of microorganisms. Acetylsalicylic acid, ibuprofen, ketoprofen, naproxen, diclofenac, and indomethacin, with pKa value from 4.9 to 4.1 and of acidic nature, similarly to clofibrilic acid and bezafibrate (pKa 3.6) in neutral $\mathrm{pH}$, occur in ionic form and have a slight tendency to adsorb in sewage sludge. Nonetheless, at lower $\mathrm{pH}$ values, there increases adsorption of these drugs in sludge. At neutral $\mathrm{pH}$, pharmaceutical compounds are negatively charged and reside mainly in the dissolved phase of wastewater (52).

In fermented sewage sludge, adsorption of pharmaceuticals does not go on, or it takes place at a relatively low level. However, when sewage sludge is used as a fertilizer, easily adsorbing pharmaceuticals can possibly get into the environment $(2,53)$. Alder et al. (45) found that the highest content of fluoroquinolones in sewage sludge. This is confirmed by research by Giger et al. (54), who report that $80-90 \%$ of fluoroquinolones, ciprofloxacin and norfloxacin are eliminated from treated wastewater mainly by sorption on sewage sludge. In processed sludge, fluoroquinolone contents reach the values expressed in $\mathrm{mg} / \mathrm{kg}$. The most important process of removing pharmaceuticals during wastewater treatment is aerobic and anaerobic degradation. The amount of removed compounds depends on sewage sludge retention time and age and increases along with the hydraulic retention time. For example, biodegradation of diclofenac in sewage sludge occurs only after 8 days of sludge retention $(2,52)$.

Wastewater treatment processes may result in the formation of pharmaceutical conjugates (complexes with covalently bound drugs) that cause the formation of chemically active components (e.g. in the case of estradiol). Some drugs are discharged in a modified chemical form (e.g. hydrolyzed), and then intermediate products of drug transformation can occur in the treated wastewater. This is an additional, indirect source of pharmaceutical penetration into the environment $(2,52)$.

\section{Ecotoxicology}

There has been available little information on bioaccumulation of pharmaceuticals in living organisms or in the trophic chain.

The high values of adsorption coefficients in tetracycline antibiotics and fluoroquinolones observed in the soil solution cause that these substances are hardly bioavailable. The influence of antibiotics present in the soil solution on higher organisms is unlikely and has not been hitherto described in subject literature. For instance, according to the studies conducted so far, oxytetracycline and e.g. tylosin (used in veterinary medicine) that enter the soil have no effect on soil organisms, such as earthworms, springtails and pot-worms (12). On the other hand, amphetamine sulfate shows high toxicity to Daphnia spp. as well as freshly isolated rainbow trout hepatocytes.

Cyto-genotoxic effects of cocaine - that cause DNA damage, cellular apoptosis and the formation of micronuclei in cells - were also observed in the zebra mussel Dressena polymorpha. Morphine has an immunotoxic effect on freshwater mussels (Elliptio complanata), manifested by lipid peroxidation, phagocytosis reduction and esterase activity in these organisms. The ecotoxic effect of illegal pharmaceutical substances (methamphetamine) on soil microorganisms was described as stimulating dehydrogenase activity and negligible on potential nitrification activity in the studied soils (55).

The substances that are not eliminated or partially removed during wastewater treatment contaminate groundwater and can affect aquatic organisms at different trophic levels. The results of ecotoxicity tests carried out with the use of bacteria point toward the adverse effects of toxic compounds on natural bacterial populations in waters. The sensitivity of algae to antibiotic is differentiated. Selenastrum capricornutum is much less sensitive to antibiotics than Microcystis aeruginosa. Cyanobacteria are sensitive to most antibiotics, e.g. amoxicillin, benzylpenicillin, sarafloxacin, spiramycin, tetracycline, and tiamulin.

Many species of plants are susceptible to antibiotics that can affect the replication of chloroplasts (fluoroquinolones), transcription and translation (tetracyclines, macrolides, lincosamides, $\beta$-aminoglycosides), metabolic pathways of biosynthesis (sulfonamides) and synthesis of fatty acid (triclosan). Antibiotics in the aquatic environment may also adversely affect reproduction and initial development stages of aquatic organisms, which translates into a threat to entire populations. For instance, there was reported the effect of antibiotic toxicity on reproduction of D. magna and mortality of Artemia sp. LC50 of antibiotics (furazolidone) below $1 \mathrm{mg} / \mathrm{L}$ was toxic to mosquito Culex pipiens larvae, Daphnia magna and Artemia salina. Antibiotics in the aquatic environment have also an effect on the behavior of living organisms, e.g. D. magna phototaxis.

Toxic effects of antibiotics to fish have not been demonstrated unless these organisms were tested when exposed to very high antibiotic concentra- 
tions, and these are not actually found in the aquatic environment. Toxicity tests carried out on aquatic species such as Acartia tonsa, Brachydanio rerio, Leup totes reticulatus, Salmo gairdneri and Salvelinus namayeush showed no toxicity of antibiotics to these organisms. Acute and chronic toxicity tests carried out as regards commonly used antibiotics that are present in waters (sulfonamides, tetracyclines, aminoglycosides, fluoroquinolones and $\beta$ lactams) with the use of such organisms as Vibrio fischeri, Daphnia magna, Moina macrocopa, Oryzias latipes proved that the most toxic substances are: neomycin, trimethoprim, sulfamethoxazole, and enrofloxacin.

Tests of chronic toxicity of the above antibiotics indicated that neomycin at very low concentrations affects the reproduction and survival of D. magna and M. macrocopa. Cyprogloxacin at the concentration of $5 \mathrm{mg} / \mathrm{L}$ has an effect on $V$. fisheri, whereas levofloxacin and clarithromycin do not show acute toxicity to this organism. These antibiotics also show high toxicity to algae. Fluoroquinolone antibiotics are toxic to organisms such as D. magna (5-day reproduction test, EC50 minimum $7.9 \mu \mathrm{g} / \mathrm{L}$ ), Lemna minor (7-day reproduction test, EC50 minimum $53 \mu \mathrm{g} / \mathrm{L})$ and Pseudokirchneriella subcapitata alga (3-day growth and reproduction test, EC50 minimum $1100 \mu \mathrm{g} / \mathrm{L}$ ) (22).

Compounds such as fluoxetine, sertraline, norfluoxetine, and demethylextraline have also been detected in fish tissue (2).

The other point of concern are antibiotics' byproducts, potentially bioactive and more toxic, stable and mobile in the environment than their parent compounds (9). Carvalho et al. (9) indicate that byproducts can be an additional reservoir of contaminants, being potentially reversible to the parent compound.

\section{Environmental risk assessments}

The occurrence of pharmaceuticals in the aquatic environment has become a contemporary threat to the environment as a whole. Due to their complex chemical structure, these substances are not fully removed during wastewater treatment, and their unchanged forms or indirect metabolites can have an effect on contamination of the surface and ground water. The presence of pharmaceuticals in the environment, even at low concentrations, poses a potential threat to living organisms and requires new legislation with regard to their detection/identification as well as the methods of removal from the aquatic environment. There is also required monitoring to track the occurrence of pharmaceuticals in the environment, as well as their distribution and impact on living organisms. The problem of the presence of pharmaceuticals in the environment is multifaceted and calls for the active approach of many scientific disciplines, at the same time as contamination of ecosystems with pharmaceuticals forces seeking and putting into practice methods for effective removal of these substances in the process of wastewater treatment.

The occurrence of some non-steroid antiinflammatory drugs in the aquatic environment (by reason of their wide availability) and exemplary methods of their removal in the processes of wastewater treatment have been already described. Inefficient water purification and municipality wastewater treatment expose to risk the recipients of drinking water and organisms living in the receivers of treated wastewater. In the case of drinking water, in the long-term perspective, insufficient wastewater treatment may result in increased organism resistance to certain medications and a need to use higher doses to achieve the desired effect. Li (56) and Luo et al. (57) published literature reviews on, among others, the results of studies on the concentrations of NSAIDs (ibuprofen, naproxen and diclofenac) in treated wastewater discharged into the environment.

A team of researchers from the United States and China studied the occurrence, fate and persistence in the soil and water of gemfibrozil (hypolipemic drug). There were examined samples of treated and untreated wastewater from sewage treatment plants and groundwater samples from the areas located below those irrigated with treated wastewater. The results of the study showed that gemfibrozil concentrations in untreated and treated wastewaters were $3.47-63.8 \mu \mathrm{g} / \mathrm{L}$ and $0.08-19.4$ $\mu \mathrm{g} / \mathrm{L}$, respectively. In groundwater, the concentrations ranged from undetectable to $6.86 \mu \mathrm{g} / \mathrm{L}$. The results obtained showed that gemfibrozil present in wastewaters used for irrigation of arable lands can penetrate groundwaters (58).

The potential risk associated with the presence of pharmaceutical residues in the environment has become important in regulations concerning environmental protection and industry. Detection of pharmaceuticals in environmental tests increased awareness of this problem, especially in the scientific community (59). The likelihood that a compound will cause undesirable effects on the environment is estimated in the risk assessment process (44). Environmental risk assessments as regards pharmaceutical substances can be performed following the guidelines provided in e.g. Commission Directive 
93/67/EEC of 20 July 1993 laying down the principles for assessment of risks to man and the environment of substances notified in accordance with Council Directive 67/548/EEC or those issued by the European Medicines Agency (EMA).

The guidelines by EMA and those by US Food and Drug Administration (FDA) are analogous and both use environmental risk assessment systems involving risk quotient (RQ) estimates, based on predicted environmental concentrations (PECs) and predicted no-effect concentrations (PNECs) (Hernando et al. 2006). Liu et al. presented a simple risk assessment for aquatic organisms based on the literature PNEC values and measured concentrations of antibiotics in surface waters in China (61). The results were presented in Table 3 .

According to art. 8 of the Directive 2001/83/ $\mathrm{EC}$, the introduction of a medicine on the market requires an assessment of a potential environmental risk posed by a medical product, an assessment of its impact as well as that with regard to the reduction of the product negative impact on the environment (Directive 2001/83/EC, amended 2012/26/EU). An important aspect is the assessment and review of

Table 3. RQs for the antibiotics in surface water from the lake in China (based on Liu et al. 2018).

\begin{tabular}{|c|c|c|c|}
\hline Antibiotics & $\begin{array}{l}\text { Measured maximum } \\
\text { environmental } \\
\text { concentration }[\mathrm{ng} / \mathrm{L}]\end{array}$ & $\begin{array}{l}\text { Predicted no effect } \\
\text { concentration [ng/L] } \\
\text { (literature data) }\end{array}$ & RQ \\
\hline \multicolumn{4}{|c|}{ Sulfonamides } \\
\hline Sulfachloropyridazine & 4.6 & $2330(62)$ & 0.002 \\
\hline Sulfamonomethoxine & 23.1 & $1.72 \times 10^{6}(63)$ & $1.34 \times 10^{-5}$ \\
\hline Sulfapyridine & 85 & $5280(62)$ & 0.016 \\
\hline Sulfadiazine & 505 & $135(63)$ & 3.74 \\
\hline Sulfathiazole & 134.5 & $200(64)$ & 0.67 \\
\hline Sulfacetamide & 48.26 & $83.594(65)$ & 0.00058 \\
\hline Sulfamethazine & 654 & $1277(66)$ & 0.51 \\
\hline Sulfamethoxazole & 940 & $27(67)$ & 34.81 \\
\hline Sulphachloropyridazine & 43.3 & $2330(62)$ & 0.019 \\
\hline \multicolumn{4}{|c|}{ Trimethoprim } \\
\hline Trimethoprim & 40.8 & $16.000(68)$ & 0.0026 \\
\hline \multicolumn{4}{|c|}{ Quinolones } \\
\hline Norfloxacin & 156 & $16(63)$ & 9.75 \\
\hline Ofloxacin & 713.6 & $11.3(69)$ & 63.15 \\
\hline Ciprofloxacin & 112.3 & $5(70)$ & 22.46 \\
\hline Enrofloxacin & 81.7 & $28.8(69)$ & 2.84 \\
\hline Sarafloxacin & 28.2 & $15(68)$ & 1.88 \\
\hline Lomefloxacin & 53.85 & $19.9(69)$ & 2.71 \\
\hline \multicolumn{4}{|c|}{ Tetracyclines } \\
\hline Oxytetracycline & 90.3 & $1040(71)$ & 0.087 \\
\hline Tetracycline & 87.9 & $3310(72)$ & 0.027 \\
\hline Chlortetracycline & 142.5 & $9310(73)$ & 0.015 \\
\hline \multicolumn{4}{|c|}{ Macrolides } \\
\hline Erythromycin & 624.8 & $20(70)$ & 31.24 \\
\hline Roxithromycin & 314.2 & $100(74)$ & 3.14 \\
\hline Clarithromycin & 10.6 & $2(70)$ & 5.3 \\
\hline \multicolumn{4}{|c|}{ Lincosamides } \\
\hline Lincomycin & 357 & $50(63)$ & 7.14 \\
\hline
\end{tabular}


environmental effects at every stage of the life cycle of a given pharmaceutical product (LCA - Life Cycle Assessment) (59).

European law does not refer to the reduction of water contamination with drugs and hormonal substances. In 2012, the European Commission proposed 15 new compounds to be included in the list of 33 priority substances, which should be monitored as water pollution agents in the EU. These included diclofenac, ethinyloestradiol, 17-estradiol, among others.

The presence of mixtures of pharmacological compounds in the environment makes it necessary to conduct environmental risk assessments of these substances $(2,59,61)$. Currently, environmental risk assessments concern individual pharmaceutical substances. However, these do not occur in the environment alone, but as a mixture of various active compounds or their metabolites and transformation products. Mixtures of these substances have different toxicological effects as compared to single substances, but knowledge on this subject is still insufficient (75). The challenge for monitoring pharmaceuticals is the selection of appropriate analytical methods for specific types of environmental tests (2). Pharmaceuticals in the aquatic environment are not acute toxicity factors for living organisms (44, 52, 59).

Toxic effects are possible due to the chronic influence of pharmaceuticals, which determines the need to further assess threats and risks associated with their introduction into the environment, but little is known about the potential effects of such impact on aquatic organisms $(44,52)$. The use of Quantitative structure-activity relationship models (QSAR models) to predict the effects of toxicity of pharmaceutical substances used in medicine is contentious.

Some authors argue that there is not enough data available on the toxicity of pharmaceuticals, which prevents generating QSAR models. It is suggested, however, that other existing models can be used to assess the toxic effects of pharmaceuticals in the environment. It has been impossible to assess chronic toxicity of pharmaceutical substances in the aquatic environment as yet, due to the lack of sufficient data to build a QSAR model. To predict acute toxicity of pharmaceuticals in the aquatic environment, the Ecological Structure- Activity Relationships programs (ECOSAR) have been used (59).

\section{CONCLUSIONS}

Pharmaceuticals introduced into the environment may undergo various reactions, and as a result
- are completely or partially degraded. The processes towards the reduction of pharmaceutical amounts in the environment involve mainly biodegradation, hydrolysis and photodegradation (direct or indirect). The problem of environmental contamination with pharmaceuticals, more and more often concerns drinking water sources (observed concentrations range from $\mathrm{ng} / \mathrm{L}$ to $\mu \mathrm{g} / \mathrm{L}$ ), nevertheless, comprehensive information on this issue is still lacking. Ozonation and other advanced oxidation processes, physical separation methods, adsorption on activated carbon as well as membrane processes are effectively used in water treatments as to pharmaceutical residues.

Pharmaceuticals, due to their complex chemical structure, are not fully removed during wastewater treatment and their unchanged forms or metabolites can contaminate surface and ground waters, hence, they are hazardous to the environment. The presence of pharmaceuticals in the environment, even at low concentrations, is a potential threat to living organisms and requires new legislation. Furthermore, monitoring of pharmaceuticals is necessary to track their occurrence and distribution in the environment, as well as impacts on living organisms.

\section{REFERENCES}

1. Ong T.T.X., Blanch E.W., Jones O.A.H.: Environ Sci. Pollut. Res. 25, 10966 (2018).

2. Nikolaou A., Meric S., Fatta D.: Anal. Bioanal. Chem. 387, 1225 (2007).

3. Jamrógiewicz M., Merchel M.: Acta Pol. Pharma. 75, 297 (2018).

4. Ferrari B., Paxeus N., Giudice R., Pollio A., Garric J.: Ecotox. Environ. Safe. 55, 359 (2003).

5. Alexy R.: in Pharmaceuticals in the Environment, 2nd ed., Kummerer K. Eds., pp. 209-221, Springer, New Jork 2001.

6. Velagaleti R.: Ther. Innov. Regul. Sci. 31, 715 (1997).

7. Boreen A.L., Arnold W.A., McNeill K.: Aquat. Sci. 65, 320 (2003).

8. Bottoni P., Caroli S.: Microchem. J. 136, 2 (2018).

9. Carvalho I.T., Santol L.: Environ. Int. 94, 736 (2016).

10. Li B., Zhang T.: Water Res. 47, 2970 (2013).

11. Kafaei R., Papari F., Seyedabadi M., Sahebi S., Tahmasebi R. et al.: Sci. Total Environ. 627, 703 (2018).

12. Hamscher G., Kuhne M., Korner U., Schedl D., Wenzel S.: Food Chem. 75, 423 (2001). 
13. Heberer T.: Toxicol. Lett. 131, 5 (2002).

14. Kunkel U., Radke M.: Environ. Sci. Technol. 42, 7273 (2008).

15. Lin A.Y.-Ch., Lin Ch.-A., Tung H.-H., Chary N.S.: J. Hazard. Mater. 183, 242 (2010).

16. Liu Q.-T., Williams H.E.: Environ. Sci. Technol. 41, 803 (2007)

17. Matamoros V., Duhec A., Albaiges J., Bayona J.M.: Water Air Soil Pollut. 196, 161 (2009).

18. Kwon J.-W., Armbrust K. L.: Environ. Toxicol. Chem. 25, 2561 (2006).

19. Liang X., Chen B., Nie X., Shi Z., Huang X., Li X.: Chemosphere 92, 1410 (2013).

20. Munoz I., Lopez-Doval J.C., Ricart M., Villagrasa M., Brix R. et al.: Environ. Toxicol. Chem. 28, 2706 (2009).

21. Yu Y., Wu L., Chang A.C.: Sci. Total. Environ. 442, 310 (2013).

22. Kümmerer K.: Chemosphere 75, 417 (2009).

23. Zou H., Radke M., Kierkegaard A., McLachlan M.S.: Environ. Sci. Technol. 49, 9881 (2015a).

24. Zou H., Radke M., Kierkegaard A., MacLeod M., McLachlan M.S.: Environ. Sci. Technol. 49, 1646 (2015b).

25. Chander V., Sharma B., Negi V., Singh Aswal R., Singh P. et al.: J. Xenobiot. 6, 5774 (2016).

26. Deo R.P., Halden R.U.: Water 5, 1346 (2013).

27. Daughton C.G., Ternes T.A.: Environ. Health Persp 107, 907 (1999).

28. Halling-Sørensen B., Nielsen S.N., Lanzky P.F., Ingerslev F., Holten Lützhøft H.C., Jørgensen S.E.: Chemosphere 36, 357 (1998).

29. Ternes T.A.: Wat. Res. 32, 3245 (1998).

30. Wilken R.-D., Ternes T.A., Heberer T.: in Security of Public Water Supplies Deininger R.A. et al. (Eds.), pp. 227-240 (2000).

31. Lam M.W., Young C.J., Brain R.A., Johnson D.J., Hanson M.A. et al.: Environ. Toxicol. Chem. 23, 1431 (2004).

32. Paiga P., Delerue-Matos C.: Sci. Total Environ. 569-570, 16 (2016).

33. Araujo L., Villa N., Camargo N., Bustos M., Garcia T., Prieto A.J.: Environ. Chem. Lett. 9, 13 (2011).

34. Tixier C., Singer H.P., Oellers S., Müller S.R.: Environ. Sci. Technol. 37, 1061 (2003).

35. Bahnmüller S., von Gunten U., Canonica S.: Wat. Res. 57, 183 (2014).

36. Nowicki P., Klos J., Kokot Z.: Acta Pol. Pharm. 71, 25 (2014).

37. Esplugas S., Bila D.M., Krause L.G.T., Dezotti M.: J. Hazard. Mater 149, 631 (2007).

38. Boleda M.R., Galceran M.T., Ventura F.: Environ. Pollut. 159 (2011).
39. Andreozzi R., Raffaele M., Nicklas P.: Chemosphere 50, 1319 (2003).

40. Archer E., Petrie B., Kasprzyk-Hordern B., Wolfaart G.M.: Chemosphere 174, 437 (2017).

41. Im J.-K., Boateng L.K., Flora J.R.V., Her N., Zoh K.-D., Son A., Yoon Y.: Sep. Purif. Technol. 123, 96 (2014).

42. Im J.-K., Heo J.H., Boateng L.K., Her N., Flora J.R.V. et al.: J. Hazard. Mater. 254, 284 (2013).

43. Nguyen L.N., Hai F.I., Kang J., Price W.E., Nghiem L.D.: Int. Biodeter. Biodegr. 85, 474 (2013).

44. Carlsson C., Johansson A., Alvan G., Bergman K., Kühler T.: Sci. Total Environ. 364, 67 (2006).

45. Alder C., McArdell C.S., Golet E.M., Kohler H.-P.E., Molnar E. et al.: Sci. Total Environ. 407, 2711 (2009).

46. Baran W., Adamek E., Ziemiańska J., Sobczak A.: J. Hazard. Mater. 196, 1 (2011).

47. Cooper E., Siewicki T., Phillips K.: Sci. Total Environ. 398, 26 (2008).

48. Rodriguez-Mozaz, S., Weinberg H.: Environ. Health Perspect. 118, 1016 (2010).

49. Watkinson A., Murby E., Kolpin D., Costanzo S.: Sci. Total Environ. 407, 2711 (2009).

50. Zuccato E., Calamari D., Natangelo M., Fanelli R.: Lancet 355, 1789 (2000).

51. Hirsch R., Ternes T., Haberer K., Kratz K.: Sci. Total Environ. 225, 109 (1999).

52. Fent K., Weston A.A., Caminada D.: Aquat. Toxicol. 76, 122 (2006).

53. Tijani J.O., Fatoba O.O., Petrik L.F.: Water Air Soil Pollut. 224, 1 (2013).

54. Giger W., Alder A., Golet E., Kohler H., McArdell C. et al.: Chimia 57, 485 (2003).

55. Pal R., Megharaj M., Kirkbride K., Naidu R.: Sci. Total Environ. 463, 1079 (2013).

56. Li W.C.: Environ. Pollut. 187, 193 (2014).

57. Luo Y., Guo W., Ngo H.H., Nghiem L.D., Hai F.I. et al.: Sci. Total Environ. 473, 619 (2014).

58. Fang Y., Karnjanapiboonwong A., Chase D.A., Wang J., Morse A.N., Anderson T.A.: Environ. Toxicol. Chem. 31, 550 (2012).

59. Crane M., Watts C., Boucard T.: Sci. Total Environ. 367, 23 (2006).

60. Hernando M., Mezcua M., Fernandezalba A., Barcelo D.: Talanta 69, 334 (2006).

61. Liu X., Lu S., Guo W., Xi B., Wang W.: Sci. Total Environ. 627, 1195 (2018).

62. Pro J., Ortiz J.A., Boleas S., Fernández C., Carbonell G., Tarazona J.V.: Bull. Environ. Contam. Toxicol. 70, 290 (2003).

63. Zhao T.H., Chen Y.H., Han W., He Y.L.: Ecol. Environ. Sci. 25, 1707 (2016). 
64. Park K., Kwak I.S.: Comp. Biochem. Physiol. C Toxicol. Pharmacol. 156, 113 (2012).

65. Zhang X.J., Bai Y.W., Zhang Y., Ma S.Q., Guo C.S., Zhang L.: China Environ. Sci. 11, 1 (2017).

66. Brain R.A., Johnson D.J., Richards S.M., Sanderson H., Sibley P.K., Solomon K.R.: Environ. Toxicol. Chem. 23, 371 (2004).

67. Ferrari B., Mons R., Vollat B., Fraysse B., Paxçaus N. et al.: Environ. Toxicol. Chem. 23, 1344 (2004).

68. Lützhøft H.C.H., Halling-Sørensen B., Jørgensen S.E.: Arch. Environ. Contam. Toxicol. 36, 1 (1999).

69. Backhaus T., Scholze M., Grimme L.H.: Aquat. Toxicol. 49, 49 (2000).
70. Isidori M., Lavorgna M, Nardelli A., Pascarella L., Parrella A.: Sci. Total Environ. 346, 87 (2005).

71. Kolar B., Arnuš L., Jeretin B., Gutmaher A., Drobne D., Durjava M.K.: Chemosphere 115, 75 (2014)

72. González-Pleiter M., Gonzalo S., RodeaPalomares I., Leganés F., Rosal R., Boltes K.: Water Res. 47, 2050 (2013).

73. Xu D.M., Wang Y.H., Rao G.W.: Environ. Sci. 34, 3386 (2013).

74. Yang L.H., Ying G.G., Su H.C., Stauber J.L., Adams M.S., Binet M.T.: Environ. Toxicol. Chem .27, 1201 (2008).

75. Santos L., Araujo A., Fachini A., Pena A., Delerue-Matos C., Montenegro M.: J. Hazard. Mater. 175, 45 (2010).

Received: 13.09.2018 